\title{
Aa. Vv., «Bulletin des Amis d'André Gide», n. 154
}

\section{Emanuele Kanceff}

\section{OpenEdition}

\section{Journals}

\section{Edizione digitale}

URL: http://journals.openedition.org/studifrancesi/9656

DOI: 10.4000/studifrancesi.9656

ISSN: 2427-5856

\section{Editore}

Rosenberg \& Sellier

\section{Edizione cartacea}

Data di pubblicazione: 1 décembre 2007

Paginazione: 694

ISSN: 0039-2944

\section{Notizia bibliografica digitale}

Emanuele Kanceff, «Aa. Vv., «Bulletin des Amis d'André Gide», n. 154», Studi Francesi [Online], 153 (LI III) | 2007, online dal 30 novembre 2015, consultato il 08 janvier 2021. URL: http:// journals.openedition.org/studifrancesi/9656 ; DOI: https://doi.org/10.4000/studifrancesi.9656

Questo documento è stato generato automaticamente il 8 janvier 2021.

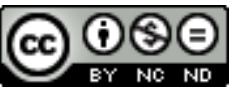

Studi Francesi è distribuita con Licenza Creative Commons Attribuzione - Non commerciale - Non opere derivate 4.0 Internazionale. 


\title{
Aa. Vv., «Bulletin des Amis d'André Gide», n. 154
}

\author{
Emanuele Kanceff
}

\section{NOTIZIA}

«Bulletin des Amis d'André Gide», n. 154, XL ${ }^{\mathrm{e}}$ année, vol. XXXV, avril 2007, pp. 201-364.

1 Alain GOULET apre questo secondo fascicolo del quarantennale della rivista con un interessante articolo su Rémy de Gourmont vu par André Gide e sull'avversione che quest'ultimo nutrì per Gourmont, dopo un iniziale periodo di amicizia. Goulet ricostruisce acutamente, sulla scorta di corrispondenze scambiate, di documenti, di pagine critiche, l'ambiguo rapporto e le sue motivazioni interiori.

Carol L. KAPLAN si occupa di un altro rapporto: Gide et Poussin. Une lecture-ekphrasis des "Faux-Monnayeurs". Questo articolo costituisce la continuazione ideale di altri due scritti della stessa autrice, pubblicati in questo stesso «Bulletin»: En quête de l'Arcadie: Gide lecteur de Poussin (n. 116, ottobre 1997) e Peinture et écriture: le mythe d'Orion dans la "Symphonie pastorale" (n. 137, gennaio 2003). Kaplan vuole mostrare l'affinità tra la mise en abyme della scrittura gidiana e quella pittorica di Poussin e come certi personaggi o certe scene dello scrittore richiamino i quadri del pittore sia per il contenuto che per la forma.

3 Una via non troppo dissimile percorre Victoria REID con il suo Gide, Rembrandt et La Leçon d'anatomie, in cui si mettono in rilievo i rapporti e le affinità tra i due personaggi, ma anche con Blanche, e le relative affinità pittoriche.

Claude FOUCART rivolge invece la sua attenzione ai rapporti dello scrittore con il Belgio e con gli intellettuali belgi, così come si leggono, tra l'altro, nel Journal e nei Cahiers de la Petite Dame. In Autour de Herman de Cunsel, questi, e non Gide, è il vero protagonista del documentato ed erudito saggio di Foucart e ancora una volta il discorso torna ad accentrarsi sugli artisti e sulla pittura. 
5 Oltre alle consuete puntate di diari inediti di Levesque e di Lambert, oltre alle consuete e sempre arricchenti rubriche, l'ultima parte del fascicolo offre un saggio di Jean CLAUDE e Pierre MASSON su Retour sur la "Correspondance André Gide-Marc Allégret", che vuole da un lato segnalare alcuni errori presenti nel volume, dall'altro portare a conoscenza dei lettori la scoperta tardiva di un certo numero di lettere di Gide a Marc, che ovviamente non hanno potuto figurare nell'edizione. 